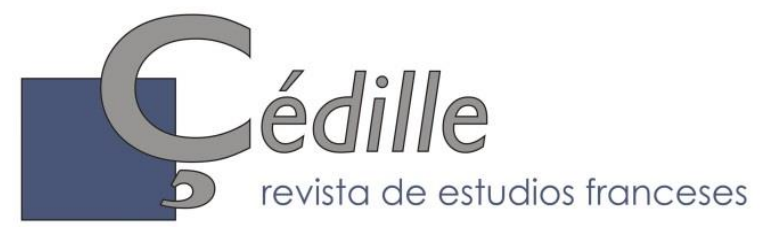

ISSN: 1699-4949

no 20 (otoño de 2021)

Varia

\title{
La epístola Eloisa to Abelard de Alexander Pope y sus traducciones e imitaciones en Francia en el siglo XVIII
}

\author{
Juan de Dios Torralbo CABALlero \\ Universidad de Córdoba \\ torralbocaballero@uco.es \\ https://orcid.org/oooo-0003-3820-9638
}

\section{Resumen}

Este artículo se ocupa del «nacimiento» de la heroida en Francia en el siglo XVIII, originado por las diversas traducciones que generó la epístola Eloisa to Abelard (1717), de Alexander Pope. El poeta inglés, siguiendo la estela iniciada por el poeta romano Ovidio, compuso un poema de 366 versos basado en la historia de los infortunados amantes Abelardo y Eloísa. Poeta muy admirado e imitado en Francia, su epístola tuvo una enorme difusión entre los escritores galos, la cual fue imitada y traducida tanto en verso como en prosa. El autor que contribuyó a la expansión y desarrollo del subgénero poético de la heroida en Francia es CharlesPierre Colardeau con su Lettre d'Héloïse à Abailard, traduction libre de M. Pope, obra publicada en 1758. Su traducción puso de moda en Francia un nuevo tipo de «lettre en vers», «épître héroïque» o «élégie», ya que tales eran los nombres que recibían estos poemas, que aportaban la expresión de pasiones y sentimientos sinceros de personajes que escribían en primera persona, emocionando a los lectores. Palabras clave: siglo XVIII, Alexander Pope, heroidas, Colardeau, traducciónimitación.

\section{Résumé}

Article qui traite de la « naissance » de l'héroïde en France au XVIIIe siècle, à l'origine des différentes traductions engendrées par l'épître Eloisa to Abelard (1717), d'Alexander Pope. Le poète anglais, suivant le modèle initié par le poète romain Ovide, composa un poème de 366 lignes basé sur l'histoire des malheureux amants Abélard et Héloïse. Poète très admiré et imité en France, son épître devait avoir une grande diffusion parmi les écrivains français, étant imitée et traduite à la fois en vers et en prose. L'auteur qui contribua à l'expansion et au développement du sous-genre poétique des Héroïdes en France fut Charles-Pierre Colardeau avec sa Lettre d'Héloïse à Abailard, une traduction libre de M. Pope, ouvrage publié en 1758. Sa traduction fit apparaître une mode en France, un nouveau type de « lettre en vers ", " épître héroïque » ou " élégie », noms qu'ont reçus ces poèmes, qui présentent l'expression des passions et des sentiments sincères des personnages qui ont écrit à la première personne, en touchant les lecteurs.

*Artículo recibido el 22/12/2020, aceptado el 31/03/2021. 
Mots clé: XVIII ${ }^{\mathrm{e}}$ siècle, Alexander Pope, héroïdes, Colardeau, imitation-traduction.

\begin{abstract}
This paper examines the «birth» of works in the tradition of the Heroides in France in the 18th century, originating with the various translations that the epistle Eloisa to Abelard (1717), by Alexander Pope, spawned. The English poet, following in the footsteps of the Roman poet Ovid, would compose a 366-line poem based on the story of the star-crossed lovers Abelard and Eloisa. A poet much admired and imitated in France, his epistle would circulate extensively amongst writers in the country, being imitated and translated both in verse and prose. The author who would contribute to the expansion and development of the poetic subgenre of works following the legacy of the Heroides in France would be CharlesPierre Colardeau, with his Lettre d'Héloïse à Abailard, a free translation of $M$. Pope, a work published in 1758. His translation would make popular a new kind of «lettre en vers», «épître héroïque» or «élégie», as these poems were termed, which featured expressions of passions and sincere feelings by their characters, who wrote in the first person, moving readers.
\end{abstract}

Keywords: 18 th century, Alexander Pope, Heroides, Colardeau, imitation-translation.

\title{
1. Introducción
}

Los fundamentos teóricos que subyacen a esta aproximación están en el concepto de «weltliteratur» - planteado por Erich Auerbach (1967: 391)— y en la historia de la traducción, es decir, en la necesidad de «historiar la traducción» tal como la conciben Francisco Lafarga y Luis Pegenaute (2013: 13), los cuales se basan en los postulados de Antoine Bernan (1984: 12) y de Valentín García Yebra (1988: 11). El objetivo central del presente trabajo ${ }^{1}$ es cartografiar la recepción del poema Eloisa to Abelard de Alexander Pope (1688-1744) en la literatura francesa del siglo XVIII, enumerando las traducciones o las versiones galas que he localizado. Como objetivo secundario, traduciré al español algunas muestras de las composiciones francesas. La metodología aplicada consiste en la búsqueda, localización y presentación de los textos franceses considerados como traducciones o versiones de la heroida:

Après six cent soixante-quinze ans, disait M. Guizot en 1838, Héloïse et Abailard reposent encore ensemble dans le même tombeau ; et tous les jours, de fraîches couronnes déposées par des mains inconnues, attestent, pour les deux morts, la sympathie sans cesse renaissante des générations qui se succèdent. L'esprit et la science d'Abailard auraient fait vivre son nom dans les livres ;

${ }^{1}$ Este trabajo se ha realizado en el marco del proyecto de investigación Portal digital de
Historia de la Traducción en España, PGC2018-095447-B-Ioo (MCIU/AEI/FEDER, UE). 
l'amour d'Héloïse a valu, a son amant comme à elle, l'immortalité dans les cours (Guizot, 1853: s.p.).

Esta afirmación es atribuida al historiador y político francés François Pierre Guillaume Guizot (1787-1874), en el «Avertissement de l'Éditeur» (Didier) a la obra de Guizot y de su mujer: Abailard et Héloïse. Essai historique. El hecho de que dos siglos después la historia de Abelardo y Eloísa siga tan «viva» y actual confiere más importancia y credibilidad a la afirmación del editor Didier.

\subsection{Eloisa to Abelard de Alexander Pope}

Alexander Pope es un escritor nacido en Londres que a los cinco años se trasladó junto a su familia a Blinfield, en Windsor, cumpliendo la legislación anticatólica imperante que incluía la prohibición de residir en un radio de diez millas de la capital. La grave enfermedad sufrida en su infancia ${ }^{2}$ lo limita de por vida a ser un inválido crónico, con una deformidad física, unido eso a las limitaciones sociales como católico que lo excluían de la Universidad y de cualquier tipo de cargo público. Hasta los 12 años recibió clases de sacerdotes, aunque luego aprende de manera autodidacta, lo que le posibilitó la lectura de la literatura inglesa, la francesa, la italiana, la latina y la griega. En 1717, se traslada a una casa de campo en Twickenham junto al Támesis, al oeste de Londres («Windsor Forest»), en la que vivirá hasta su muerte y donde recibirá las visitas de los personajes más famosos de la época. Ese es el año en que publica su conocida epístola Eloisa to Abelard, siguiendo el modelo de Ovidio en sus Epistulae Heroidum ${ }^{3}$. La originalidad

2 Posiblemente una tuberculosis en la médula espinal que afectó a la columna vertebral, deformando su cuerpo (Hammond, 1986: 9) y atrofiando su crecimiento; su estatura no superó los 137 centímetros, aunque viviera hasta los 56 años. Samuel Johnson (2009: 347) detalla que "was from his birth of a constitution tender and delicate».

3 El poema inglés está publicado en el volumen The Works of Mr. Alexander Pope (1717: 417-435). Es algo ya aceptado por la crítica que la epístola amorosa como subgénero literario fue ensayada por vez primera con Ovidio en sus Heroidas, hecho que el propio escritor resalta en su Ars amandi:

Forsitan et nostrum nomen miscebitur istis,

Nec mea Lethaeis scripta dabuntur aquis:

Atque aliquis dicet «nostri lege culta magistri Carmina, quis partes instruit ille duas:

Deve tribus libris, titulus quos signat Amorum, Elige, quod docili molliter ore legas:

Vel tibi composita cantetur Epistola voce:

Ignotum hoc aliis ille novavit opus (Ovidio, III, vv. 339-346).
Quizás mi nombre se mezcle con esos y no arrojen mis escritos a las aguas del Leteo.

Y alguien dirá: «lee de mi maestro los cultos

poemas, con los que instruyó a los dos sexos:

o de los tres libros que titula Amores, elige lo que puedas leer con suave entonación,

o recita adaptando la voz a sus Epístolas:

obras desconocidas para otros y que él inventó». 
de Ovidio se pone de relieve en la visión que el escritor transmite de sus héroes y heroínas, como si fueran seres de carne y hueso; es decir, que responden a las mismas inquietudes que los seres humanos, expresando las mismas sensibilidades y transmitiendo las mismas emociones. Estructuralmente las Heroidas son un conjunto de cartas, veintiuna, que heroínas de la mitología escriben a sus amados que las han abandonado4. En el siglo XVIII, cuando los escritores adoptan sobremanera la forma de la epístola y el tono de la elegía, Ovidio era un escritor modélico. Las Heroidas ovidianas pueden compararse a las elegías de Propercio o de Tibulo. Esta tradición es perpetuada en suelo inglés por el neoclásico Alexander Pope, que vuelve a poner de moda este tipo de poesía con su poema de 366 versos titulado Eloisa to Abelard, publicado en $1717^{5}$.

Las traducciones de poesía de Pope, sus ensayos de crítica o moral y sus sátiras lo convierten en el poeta más importante de su época, elevando el dístico o pareado heroico, que ya había sido realzado por John Dryden, a su máxima perfección al utilizarlo con excepcional brillantez y más allá de lo que ningún poeta había logrado anteriormente. El éxito del pareado heroico propicia que se convierta en la forma poética dominante del siglo. Pope lo aplica en su propia obra con la que desarrolla una carrera literaria paradigmática, la cual le permite lograr fama en vida no solo en Inglaterra, sino en todo el continente europeo. Como bien afirma una estudiosa de la obra de Pope:

La publicación en 1717 de Eloise to Abelard le supuso al autor un éxito inmediato. En ella Pope imitaba el género de las epístolas heroicas de Ovidio y basaba su argumento en las cartas de Abelardo y Eloísa traducidas por John Hugues en 1713. En esta época de su vida, atormentada en cuanto a los sentimientos afectivos, Pope se sentía atraído por la heroína inteligente, lúcida, toda ella vibrante de pasión y de una sensibilidad exquisita que es Eloísa. El poeta vive, en esos momentos, en un clima psicológico favorable a la creación de un poema de amor, pues los sentimientos que experimenta por Martha Blount y Lady Mary Wortley Montagu no son extraños a la génesis de Eloisa to Abelard: la tensión provocada por la marcha de esta última para Oriente aguza su sensibilidad y explica, en cierta medida, la atmósfera

\footnotetext{
4 Sobre las Heroidas de Ovidio es muy recomendable la edición de Francisca Moya del Baño (1956). Un estudio sobre las diferentes epístolas amorosas se encuentra en la obra de Manuela Álvarez Jurado (1998). Una muy buena Antología de Epístolas es la de Francisco López Estrada (1960). Esta última no incluye solo epístolas amorosas o heroidas, sino todo tipo de epístolas.

5 Para el poema de Pope remito a los trabajos de García Calderón (2007: 49-80) y Lastra y García Calderón (2017: 139-150).
} 
envolvente y hechizante de la obra. Por otra parte, la expresión «romantic» aparece reiteradamente en la correspondencia de Pope entre 1716 y 1720 . El término es utilizado en el sentido de «rockless», «fervent», «unrestrained», siendo este frenesí, esta desmesura, no habituales en el poeta inglés, las que dan a Eloise to Abelard su carácter único (García Calderón, 2007: 71).

Para la composición de su epístola, Pope se valió de una traducción del poeta, ensayista y traductor inglés John Hughes (1677-1720): Letters of Abelard and Heloise ${ }^{6}$. La traducción de Hughes provenía, a su vez, de una de Bussy Rabutin, de quien trataré en el siguiente epígrafe, titulada Les Lettres de messire Roger de Rabutin, comte de Bussy, lieutenant général des armées du roi et maître de camp général de la cavalerie française et étrangère (París, Florentin et Pierre Delaulne, 1697)7.

\section{Traductores e imitadores franceses}

Antes de que surja la moda en Francia de la imitación de Pope, debida fundamentalmente a la traducción de Colardeau, existía una traducción de Roger de Rabutin, comte de Bussy (conocido como Bussy-Rabutin) ${ }^{8}$, de 1697: Les Lettres de messire Roger de Rabutin, comte de Bussy, lieutenant général des armées du roi et maître de camp général de la cavalerie française et étrangère, (París, Florentin et Pierre Delaulne)9 ${ }^{9}$, reimpresa varias veces desde esa fecha. Las cartas, dos de Eloísa y una de Abelardo, respuesta a la primera de ella, están incluidas en la «Seconde Partie» y ocupan de la página 117 a la 150, de las cuales las primeras son una explicación de la historia entre los dos amantes:

Pour mieux entendre cette lettre, il faut sçavoir qui étoient Heloïse \& Abelard. Celui-ci vivoit en 1170. Sous le regne de Louis le Jeune, \& fut celebre par son esprit \& par ses malheurs.

\footnotetext{
${ }^{6}$ Posteriormente a la obra de Pope, 1717, la traducción de Hughes se publicaría en un volumen o antología con las dos traducciones y alguna más, por ejemplo, esta: LETTERS OF Abelard and Heloise. To which is prefix'd A PARTICULAR ACCOUNT OF THEIR Lives, Amours, and Misfortunes. BY THE LATE JOHN HUGHES, ESQ. Together with the POEM OF ELOISA TO ABELARD. BY MR. POPE. And, (to which is now added) the POEM OF ABELARD TO ELOISA, BY MRS. MADAN. LONDON: Printed for W. OSBORNE, and T. GRIFFIN, 1782.

7 Para esta cuestión remito al trabajo de Jean-Noël Pascal (2003: 221-234).

${ }^{8}$ Roger de Rabutin, comte de Bussy (conocido como Bussy-Rabutin, 1618-1693) era un militar y escritor célebre por su comportamiento libertino, así como por su ingenio y su causticidad, notoria es también su amistad y correspondencia con su prima, la célebre epistológrafa Madame de Sévigné.

9 Sobre la edición de las cartas, véase R. Duchêne (2006: 184-194). Sobre la obra epistolar de Bussy, véase C. Rouben (1974).
} 
Heloïsse étoit une fille de qualité ; rien n'étoit plus aimable qu'elle pour le corps \& pour l'esprit. Elle n'avoit que quinze ans, lorsque les parens qui n'épargnoient rien pour son éducation, mirent auprès d'elle Abelard, le plus poli \& le plus habile homme de son temps. Dès qu'il l'a vit, il l'aima, \& ne soupira pas longtemps sans succés. Fulbert Chanoine de l'Eglise de Paris, Oncle d'Heloïsse, qui aimoit fort Abelard, s'apperçut bientôt de son amour, \& connut avec douleur que les leçons de tendresse faisoient dans Heloïsse plus de progrés que celles de la Philosophie. Outré de ce malheur il résolut de s'en venger. Abelard s'en défia, \& pour prévenir les malheurs dont il étoit menacé, il consentit, quoi qu'il se fust destiné à l'Eglise, d'épouser Heloïsse en secret d'accord avec l'Oncle. Mais cela n'appaisa Fulbert qu'en apparence. Il corrompit un domestique d'Abelard pour faire entrer dans la Chambre de son Maître endormi un homme, qui le rasoir à la main (sans le faire mourir) le punit de son crime, \& le mit en état de ne le plus commettre.

Cette action ne demeura pas impunie. Abelard poursuivit Fulbert, qui par Arrest en perdit ses biens. L'exécuteur fut condamné à avoir les yeux crevez, \& à souffrir par la main du Bourreau le même supplice qu'il avoit fait souffrir à Abelard. Le Philosophe prit des mesures conformes à l'état où on l'avoit mis. Il se retira parmi des Moines, \& obligea Heloïsse de se mettre dans un Convent ; \& soit par amour ou par indifférence, il l'engagea à faire profession, avant qu'il fust déterminé à faire des Vœux. Lui de son côté pour soutenir le dessein de la retraite, expliquoit les Actes des Apôtres aux Moines de Saint Denys, où il s'étoit retiré ; \& par erreur ou par malice il soutint que Saint Denys l'Areopagite n'étoit jamais venu en France.

Il étoit dangereux alors d'avoir des sentimens contraires aux interêts des Moines : tous s'éleverent contre lui ; \& Abelard qui ne vouloit pas se dédire, \& qui ne pouvoit resister à tant d'ennemis, fut obligé de se retirer dans un desert proche de Nogent.

Ses malheurs lui donnerent de la réputation. Les Sçavans le chercherent ; on le trouva \& on lobligea d'enseigner ; ce qu'il fit avec tant de succés, qu'en peu de temps il amassa de grands biens, dont il fit bâtir une Chapelle \& une Maison sous le nom du Paraclet.

A peine fut-il établi dans sa solitude, qu'on l'accusa de cabaler : Il fut obligé d'en sortir pour se justifier, \& il demanda permission à l'Evêque de Troye d'y établir une Communauté de filles : il l'obtint, \& appella Heloïsse 
pour gouverner ce Monaster ; où l'ayant établie il se retira. Pendant son absence il écrivoit fort souvent à un de ses amis proche du Paraclet. Une de ses lettres étant tombée entre les mains d'Heloïsse, la curiosité naturelle à son sexe la lui fit ouvrir \& lire ; \& la douleur de voir un autre qu'elle recevoir des nouvelles de son Amant, l'obligea de lui écrire cette lettre ${ }^{10}$.

Aunque la traducción de Bussy Rabutin, en opinión de su pariente Mme de Sévigné, no parecía ajustarse demasiado al original, será durante seis décadas (hasta la publicación de la de Colardeau, en 1758) el modelo que siguen todos los imitadores de Pope, ya sean estos poetas o prosistas. Lo curioso del caso, por inaudito que parezca, es que estos imitadores o traductores no parecían conocer los textos originales en latín, pues remiten todos ellos a Bussy Rabutin. Contribuyó a esclarecer el asunto el hecho de que en 1723 el carmelita descalzo e historiador François Armand Gervaise (1660-1761), abad de Nuestra Señora de La Trappe y conocido como Dom Gervaise, descubriera el manuscrito que el magistrado y escritor François d'Amboise (1550-1619) había editado con las obras de Abelardo, en 1616, gracias a sus investigaciones en la abadía del Paraclet. La conocida como «Edición Dom Gervaise» llevaría por título: Les véritables lettres d'Héloïse et d'Abailard, tirées d'un ancien manuscrit latin, trouvé dans la bibliothèque de François d'Amboise, conseiller d'État; traduites par l'auteur de leur vie, avec des notes historiques et critiques très curieuses (1722-23, 2 vol. in-12. París; réimprimées en 1796). Desde ese momento, los investigadores serios podían contrastar las imitaciones no solo con Pope y Colardeau, sino también con su original latino.

Si bien es cierto que fue Charles Pierre Colardeau quien puso el subgénero de la heroida de moda, dado el inmenso éxito que alcanzó su imitación de Pope al publicar en 1758 su primera heroida: Héloïse à Abailard, antes de él aparecieron algunas traducciones-imitaciones dignas de mención. Luego, la heroida de Colardeau animó a otros escritores a ocuparse del tema, siguiendo la nueva moda, ya fuera en «lettre en vers», en «épître héroïque» o en «élégie», diversas formas de poemas que ponían en escena todo tipo de personajes, como de situaciones y temas. No obstante, con el fin de no perder el hilo conductor de este trabajo, me ocuparé de las traducciones o versiones que precedieron a la de Colardeau y de algunas posteriores. Citaré únicamente las imitaciones-traducciones que alcanzaron alguna difusión y traduciré aquellas en verso cuyo mérito así lo requiera.

\subsection{Les Lettres d'Héloüse et d'Abailard, mises en vers françois par le sieur P. F. G. de Beauchamps (1714)}

$\mathrm{Su}$ autor respondía al nombre de Pierre-François Godard de Beauchamps (1689-1761), parisino de vida poco conocida, novelista libertino, a

${ }^{10}$ Les Lettres de messire Roger de Rabutin... Seconde Partie, pp. 117-120. 
veces de modo anónimo; es destacable su faceta de traductor y de escritor de comedias (representadas todas en el «Théâtre Italien»); es uno de los iniciadores en Francia de la historia del teatro, que segmenta mediante cronologías precisas («de Jodelle à Garnier, de Garnier à Hardy, de Hardy à Corneille, depuis Corneille»). Sus Lettres d'Héloïse et d'Abailard fueron reeditadas en 1721 (París, Jacques Collombat), 1737 (París, Prault père), 1758, 1777 y 1841. Veamos las primeras estrofas de la respuesta de Abelardo a la primera carta de Eloísa, que es una muestra de la rebelión de Abelardo contra Dios, a quien increpa con rabia ${ }^{11}$ :

RÉPONSE D'ABAILARD A HELOÏSE

J'ai reçû votre Lettre, \& je n'ose vous dire Dans quel état funeste elle a sçû me réduire :

Mon trouble me fait honte, \& mon cœur abbatu

Veut en vain rappeller sa mourante vertu. Aussi foible que vous, plus criminel encore, Je me sens consumer du feu qui vous devore. Eh ! comment voulez-vous que je guide vos pas ?

Je m'égare moi-même, \& ne me connois pas.

De vos maux \& des miens la trop vive peinture De mes desirs éteints réveille le murmure.

Déja je commençois, oubliant mon malheur, A ne plus regretter un frivole bonheur ;

Déja je commençois, moins rempli de vos charmes,

A trouver des douceurs à répandre des larmes :

Et la grace en mon cœur allumant son flambeau,

Effaçoit le vieil homme, \& formoit le nouveau.

Vous avez tout détruit. Qu’une Epouse est puissante

!

Et qui peut résister aux soupirs d'une Amante ?

Inutile raison! Chimerique devoir !
RESPUESTA DE ABELARDO A ELOÍSA

Recibí vuestra carta, y no oso deciros en qué funesto estado ha podido mermarme; mi amor me da vergüenza, y mi abatido pecho

recordar quiere en vano su virtud agonizante. Tan débil como vos, aún más criminal, siento que me consumo del fuego que os devora. Pues ¿cómo pretendéis que guíe vuestros pasos?

Yo mismo estoy perdido, y ya no me conozco. La viviente pintura de todos nuestros males de mis deseos calmados despierta el murmurio. Ya había empezado, mi desgracia olvidando, a no echar de menos una frívola dicha; ya había empezado, lejos de vuestro hechizo,

a encontrar paliativos en derramar mis lágrimas:

y la gracia en mi alma, alumbrando su llama,

borraba al hombre de antes, y formaba a otro nuevo.

Vos todo lo habéis roto iCuán fuerte es una esposa!

¿Y quién resistir puede la queja de una amante?

¿La razón es inútil! iEl deber es utópico!

${ }^{11} \mathrm{El}$ texto fuente es la edición de 1714 (Beauchamps, 1714: 28-30). En lo que atañe a las traducciones aquí realizadas, es oportuno indicar que el texto fuente, como regla general, está compuesto por versos de doce sílabas llamados «alexandrins», "grands vers» 0 «vers héroïques», los cuales vierto mediante alejandrinos españoles, es decir, en versos de catorce sílabas con sus dos hemistiquios correspondientes, sin tener en cuenta la rima. Considero que la rima encorseta excesivamente al traductor y lo lleva a una búsqueda léxica que resulta estéril en muchas ocasiones. Mediante la elaboración de dicho cómputo silábico en el texto meta aspiro a cultivar cierto esquema prosódico y métrico en los términos postulados por James S. Holmes (1970: 94) y por Armin Paul Frank (1991: 116-117). De esta forma, priorizo fundamentalmente el sentido y mantengo la materia textual de forma lo más paralela posible respecto a la plántula, a caballo entre la «metaphrase» y la «paraphrase» según la tríada teorizada por John Dryden (1962: 268). No he tenido en cuenta las traducciones existentes en español. Agradezco al profesor García Peinado su revisión. 
Rien ne peut de l'amour balancer le pouvoir. Dans un Temple brisé trouves-tu des délices,

Dieu cruel ? Cherche ailleurs de plus doux sacrifices :

Regne sur les vivans ; qu'ils sentent tes transports ; Mais cesse de vouloir les inspirer aux morts : Allez, \& trop long-temps soumis à ton empire, J'ai vêcu sous tes loix, souffre que je respire. Terrible contre-temps, où me réduisez-vous ? N'avois-je pas du Ciel épuisé le courroux ? Falloit-il qu'une Lettre, écrite pour une autre, Troublât tout à la fois mon repos \& le vôtre ? Je l'avouë, Heloïse, attendri par ses pleurs, Je voulus d'un ami moderer les douleurs ; Je crus que de nos maux une fidelle image Contre son desespoir armeroit son courage ; Et loin d'imaginer qu'un sort capricieux Dût jamais exposer cette Lettre à vos yeux, Mon cœur, à sa pitié s'y livrant sans contrainte,

Luy peignoit les rigueurs dont je ressens l'atteinte ;

Afin que comparant mes malheurs \& les siens, Il oubliât ses maux, \& déplorât les miens.

Ainsi, de nos desseins confondant la prudence,

Dieu juste ! tu détruis notre aveugle esperance ;

Et ta main, où tu veux nous traînant malgré nous,

Accomplit tes Arrêts, \& signale tes coups :

Tu rebutes un cœur profané par le crime,

D 'une flâme insensée odieuse Victime.

Heureux, je te fuyois, \& sans te consulter,

Malheureux, dans tes bras j'ay couru me jetter.

Plein de mon desespoir \& de mon infortune, Je ne te consacrois qu'une vie importune.

Privé de mes plaisirs, mortel présomptueux, Je couvrais ma douleur d'un dehors vertueux ;

Et quand je paroissois te faire un sacrifice,

Je me vengeois du monde, \& de son injustice.
Nadie del amor puede nivelar el poder.

¿En un Templo arruinado encuentras tus placeres,

Dios cruel? Busca lejos sacrificios más dulces:

reina sobre los vivos; que sientan tus violencias; mas deja de querer inspirar a los muertos: vete, y por largo tiempo somete a tu imperio viví bajo tus leyes, consiente en que respire. Terrible contratiempo, ¿adónde me relegas? ¿No había ya agotado la cólera del Cielo? ¿Era preciso que una carta, escrita por otra, turbase al mismo tiempo mi reposo y el vuestro? Lo confieso, Eloísa, débil por tus sollozos, quise de un amigo moderar los dolores; creí que una imagen fiel de nuestros males contra su desespero blindaría su ánimo; y lejos de creer que una suerte volátil nunca exponer debiera la carta a vuestros ojos, mi corazón, piadoso, sin sujeción confiándose,

le trazó los rigores de la agresión que siento;

para que comparando mi desdicha y la suya, olvidase tus males, y los míos deplorase.

Así, de nuestros planes turbando la prudencia,

ijusto Dios!, tú destruyes nuestra ciega esperanza;

y tu mano, do quieres guiarnos a pesar nuestro,

cumple tus veredictos, $y$ señala tus golpes;

a un corazón arredras mundano por el crimen, con una enorme llama de víctima odiosa.

Feliz, de ti huía, y sin preguntarte antes,

desdichado, en tus brazos he corrido a echarme.

Lleno de desespero y de mi infortunio, te consagré tan solo una vida insufrible.

Privado de mis gozos, mortal presuntuoso, tapaba mi dolor con un exterior virtuoso;

y cuando parecía hacerte un sacrificio, me vengaba del mundo, y de su injusticia.

\subsection{Traducción de Pierre-Joseph Fiquet Du Bocage (1751)}

De 1751 es la Épître d'Héloïse à Abailard, incluida en el volumen Mélange de différentes pièces de vers et de prose. Traduites de l'anglais d'après Mdmes Elize Haywood \& Suzanne Centlivre, Mrs Pope, Southern and autres. Atribuida, en múltiples ocasiones, posiblemente de manera errónea, a su mujer Marie-Anne Du Bocage, famosa «salonnière» de Rouen 
(1710-1802) que desarrolló su actividad literaria en París, donde abrió un Salon, la traducción, directamente de la epístola inglesa de Pope, en prosa, es más factible que fuera de Pierre-Joseph Fiquet Du Bocage (1700-1767). El papel de ella considero que es el de la investigadora que encontró en Londres, en 1751, una edición anotada de las obras de Alexander Pope (The Works of Alexander Pope, London: Knapton, 1751), en la que estaba incluida la epístola Eloisa to Abelard, que Du Bocage tradujo, la cual se inserta en un volumen de obras inglesas titulado: Mélanges de différentes pièces de vers et de prose traduites de l'anglais (Berlin, 3 t., 1751). Parece probable que Feutry tuviera sobre la mesa esta versión francesa de la epístola de Pope para componer su traducción, aunque el título de esta fuera: Épitre d'Héloìse à Abélard. Traduite de M. Pope, et mise en vers par M. Feutry. Veamos el «Avertissement» que precede a la epístola:

Abailard \& Héloïse vivoient dans le douzième siècle. Ces deux personnes furent les plus distinguées de leur tems, par les lumières de leur esprit, \& les graces de leur figure : mais rien ne les rendit plus célébres que leur passion infortunée. Après une longue suite de malheurs, ils se retirent chacun dans un Couvent séparé, \& y consacrent le reste de leurs jours aux devoirs de la Religion.

Ce fut quelque tems après leur séparation, qu'une Lettre d'Abailard adressée à un ami, \& qui contenoit l'Histoire de ses malheurs, tomba entre les mains d'Héloïse. Cet écrit réveilla toute la tendresse, \& occasionna ces fameuses Lettres, qui peignent si vivement le combat de la nature \& de la grace. Celle-ci en est imitée, \& tirée en partie (Bocage, 1751: 3-4).

\subsection{Traducción de Aimé Feutry (1751)}

De 1751 es la traducción del escritor Aimé-Ambroise Joseph Feutry que es el traductor de versos grandilocuentes fúnebres, así como de reflexiones filosóficas sobre la precariedad de la grandeza. Es el imitador de los ingleses James Thomson, Alexander Pope y Edward Young que adquiere cierta celebridad gracias a Le Temple de la mort (1753) y Les Tombeaux (1755), que son precedentes de las traducciones de Pierre Le Tourneur sobre Young y Hervey los cuales ponen de moda a la denominada «Graveyard School», o «Escuela de los Cementerios» ${ }^{12}$.

Feutry vertió el poema de Pope con el título Épitre d'Héloïse à Abélard, traduite de M. Pope, et mise en vers par M. Feutry. Veamos la transcripción de la advertencia preliminar del autor, «Au lecteur», donde Feutry realza la valía de Pope, los rasgos caracterológicos del texto inglés, así como la conveniencia de compartirlos en francés; registramos también las primeras estrofas de su traducción ${ }^{13}$ :

${ }^{12}$ Sobre Aimé Feutry remito al artículo de Miguel Ángel García Peinado (2005: 1-21). ${ }^{13}$ La obra tuvo una segunda edición en Londres, 1658, que fue reeditada en 1760 (Recueil de poésies fugitives) y en 1771 (Opuscules Poétiques et Philologiques de M. Feutry). Los 
Voici une Traduction d'un des plus beaux morceaux de Poésie du célèbre $M$. Pope. Ce sujet, quoiqu'usé et rebattu, devient nouveau parla façon dont il l'a traité : on y retrouve partout le Poète Anglais, ce feu, ces images, et ces traits qui le caractérisent.

Les pièces fugitives et les fragmens de cet illustre auteur doivent nous être trop précieux pour ne pas tenter de les faire passer dans nôtre langue, qui est également susceptible de force et de beauté.

Des Personnes qui s'intéressent à moi ayant lu ce Poème, m'ont engagé à le rendre public ; j'y ai consenti d'autant plus aisément, que l'ayant fait sur une bonne traduction, il n'y a pas grand mérite à l'avoir versifié (Feutry, 1751: 1).

\section{ÉPÎTRE D'HÉLOÍSE À ABÉLARD}

Dans ce sombre désert, solitude tranquille, Séjour de l'innocence, \& des vertus l'asyle, Où mon ame \& mes yeux vers le Ciel élancés,

Ne peuvent nuit \& jour le contempler assez,

Qui peut venir troubler ma retraite profonde?

Loin des plaisirs bruyans \& des erreurs du monde,

Quel souvenir rallume un feu séditieeux ?

Mon cœur veut-il franchir l'ençeinte de ces lieux ?

Dans ce moment cruel me connois-je moi-même !...

Hélas !... j'aime toujours... C'est Abélard que j'aime

La trop foible Héloïse adore encor ses traits.

Nom redoutable \& cheri... que vous m'offrez d'attraits !

Ne le prononçons point : ma voix est consacrée

A célébrer de Dieu la majesté sacrée ;

Cachons-le dans mon cour, qu'il y soit avec lui,

Que leurs traits confondus se mêlent aujourd'hui.

Ne l'écris point ma main... Mais ce nom plein de charmes

Déjà s'offre à mes yeux... Effacez-le mes larmes !

Je les répands en vain, mon amour me trahit, Mon cœur dicte toujours \& ma main obéit.

\section{EPÍSTOLA DE ELOÍSA A ABELARDO}

En este oscuro yermo, aislamiento tranquilo, estancia de inocencia, $y$ asilo de virtudes, donde mi alma y mis ojos hacia el Cielo elevados,

no pueden día y noche bastante contemplarlo,

¿quién a turbar vendrá mi profundo retiro?

Lejos de ardientes goces y de errores mundanos, ¿qué recuerdos reavivan un fuego sedicioso? ¿Mi alma franquear quiere de ese lugar los muros?

iEn este instante cruel me conozco a mí mismo!

iAy!..., sigo amando... Sigo amando a Abelardo, la muy débil Eloísa, adora aún sus rasgos.

iGenial nombre y querido... cuán atractivo sois!

No debo pronunciarlo: mi voz he consagrado

a celebrar de Dios la sacra Majestad; en mi alma ocultémoslo, que en ella esté con él,

sus rasgos se confundan y hoy allí se mezclen.

iMano mía no escribas... Mas este este dulce nombre

se muestra ante mis ojos... Mis lágrimas, borradlo!

en vano las derramo; me traiciona mi amor, siempre el corazón dicta y mi mano obedece.

versos proceden de la primera edición (Feutry, 1751: 3-7). También hemos consultado Opuscules Poétiques (Feutry, 1771: 11-13). 
Vous, inflexibles murs ! secrets dépositaires Des sincères remords, des peines volontaires ; Rochers affreux ! témoins des tourmens de mon cœur ;

Vous, caverne profonde, où regne la terreur ;

Vases saints ! devant qui nos Vierges gémissantes

Lèvent des yeux éteints \& des mains languissantes

D’ossemens précieux, triste \& froid monument,

Qu'entourent le silence \& le recueillement ! Comme vous insensible, à moi-même barbare, Ces cilices, ces fers, que le zèle prépare,

N'ont-ils pas mille fois, par de cruels efforts,

Sans éteindre mes feux, ensanglanté mon corps?

Dieu vainement sur moi veut avoir l'avantage, L'homme asservit mon cœur, ou du moins le partage ;

Mon amour indompté ne connoît plus de frein, Les larmes \& les temps se succèdent en vain.

A mes vives douleurs il n'eft point d'intervalle ; A l'aspect imprévu d'une Lettre fatale, Je frémis... \& voyant mon nom baigné de pleurs,

Je tremblai d'y trouver quelques nouveaux malheurs ;

Chaque mot m'effrayoit, me remplissoit d'alarmes

Je versois, en lisant, un déluge de larmes.

Gémissant sur l'ennui de mon triste séjour,

Je vous voyois, tantôt esclave de l'amour,

Tantôt vainqueur, le fuir dans ce lieu solitaire

Où de l'austérité la rigueur salutaire

Détruit les passions dans nos cœurs combattus

Et développe en eux le germe des vertus.
iVosotros, firmes muros! Secretos celadores de sinceros pesares, de penas voluntarias; ifeos peñascos! Testigos del tormento de mi alma;

Vos, caverna profunda, en la que el terror reina;

iSanto cáliz frente al que nuestras llorosas Vírgenes

alzan extintos ojos y manos abatidas;

osamentas preciosas, triste y frío monumento

que envuelven el silencio y el recogimiento! Como vos insensible, bárbaro hasta conmigo, el cilicio y los hierros que el celo prepara, ¿no han ensangrentado, por crueles esfuerzos,

sin apagar mis fuegos, mil veces mi organismo?

Sobre mí, Dios en vano quiere tener ventaja, subyuga el hombre mi alma, o al menos la comparte;

mi indómito amor ya no conoce freno, las lágrimas y el tiempo se suceden en vano.

Para mi gran dolor no hay descanso alguno; ante lo inesperado de una carta fatal, tiemblo..., y al ver mi nombre bañado por las lágrimas,

me estremecí hallando allí nuevas desgracias;

me asustaban las frases, me llenaban de alarmas;

derramaba, al leerla, un diluvio de lágrimas. Gimiendo ante el hastío de mi triste estancia, os veía, a veces esclavo del amor, vencedor otras, huir a este lugar desierto, donde del ascetismo el rigor saludable destruye las pasiones en nuestra porfiada alma y desarrolla en él de la virtud el germen.

\subsection{Traducción del Abbé Gabriel-François Coyer (1757)}

Gabriel-François Coyer (1707-1782), jesuita y posteriormente sacerdote secular, fue preceptor del duque de Bouillon, miembro de la «Académie de Stanislas» (en Nancy) y de la «Royal Society de Londres». Hombre de una gran cultura, su obra comprende investigaciones históricas y económicas, novelas filosóficas y panfletos espirituales de gran agudeza e ingenio, reunidos muchos de ellos bajo el título Bagatelles Morales (tome I). En todos sus ensayos asombra por la amplitud y osadía de sus puntos de vista, defendiendo siempre el ideal de una sociedad fundada sobre el trabajo de todos sus componentes, aspecto con el cual se convirtió en uno de los más 
importantes precursores de las teorías de la igualdad en el siglo XVIII, particularmente de Rousseau. Su buena pluma en todos los temas que toca merece ser rescatada del olvido en que han caído sus obras. Fue también traductor de inglés a su lengua.

Épître d'Héloïse à Abailard, traduite de l'Anglois de M. Pope sale de las prensas por vez primera en abril de 1757 en Journal Etranger: Ouvrage Periodique (Coyer, 1757: 153-170). Así lo he constatado en dicha publicación periódica. En el tomo segundo de sus obras consta una nota a pie de página que, además de confirmar lo antedicho, compara la traducción en prosa del clérigo con la traducción en verso de Colardeau. Dicha nota arguye como ventaja la mayor literalidad de la versión en prosa y reconoce la ornamentación o la mayor riqueza de la poesía, coligiendo el éxito de ambas rescrituras en estos términos:

Cette traduction en prose n'a été imprimée que dans le Journal Etranger (Avril 1757). Elle a précédé la traduction en vers par M. Colardeau. La première est plus littérale, plus exacte ; c'est l'avantage de la prose. La seconde est plus riche, plus ornée ; c'est le mérite de la poésie. L'une \& l'autre ont eu un succès marqué. (Coyer, 1783: 432)

Para que pueda apreciarse la exactitud de su juicio, transcribo el comienzo de la epístola, junto con el original de Pope:

ELOISA TO ABELARD

(A. POPE)

In these deep solitudes and awful cells, Where heav'nly-pensive contemplation dwells,

And ever-musing melancholy reigns;

What means this tumult in a vestal's veins?

Why rove my thoughts beyond this last retreat?

Why feels my heart its long-forgotten heat?

Yet, yet I love! - From Abelard it came, And Eloisa yet must kiss the name.

Dear fatal name! rest ever unreveal'd, Nor pass these lips in holy silence seal'd. Hide it, my heart, within that close disguise,

Where mix'd with God's, his lov'd idea lies:

$\mathrm{O}$ write it not, my hand-the name appears

Already written-wash it out, my tears! In vain lost Eloisa weeps and prays, Her heart still dictates, and her hand obeys.
ÉPÎTRE D’HÉLOÏSE À ABAILARD

(G.-F. COYER)

Dans cette profonde solitude, dans cette retraite où la terreur habite avec la contemplation \& la sainteté, où regnent le silence \& le repos qui signifie cette tempête qui s'élève dans les sens d'une Vestale ? Pourquoi mes pensées volentelles loin de cet azile ? Pourquoi mon cœur ressent-il une chaleur si longtems oubliée ? Oui, oui, j'aime encore. Cet écrit vient d'Abailard, \& Héloïse baise encore son nom.

O nom cher \& fatal ! reste à jamais dans le secret de mon cœur ; mes lèvres, ne le prononcez pas, vous êtes consacrées au silence. Mon ame, cachez-le dans cette profondeur, où l'idée de Dieu \& une image plus chère se confondent. $\mathrm{O}$ ma main, garde-toi de l'écrire... Ciel ! le voilà presque écrit. Coulez mes larmes, \& effacez-le. Mais c'est envain qu'Héloïse pleure, qu'Héloïse prie, son cœur dicte \& sa main obéit.

Prisons de la vertu, dont la sombre enceinte ne renferme que des repentirs sans crime \& des pénitences volontaires ; \& vous froides reliques que nous honorons de nos 
Relentless walls! whose darksome round contains

Repentant sighs, and voluntary pains: Ye rugged rocks! which holy knees have worn;

Ye grots and caverns shagg'd with horrid thorn!

Shrines! where their vigils pale-ey'd virgins keep,

And pitying saints, whose statues learn to weep!

Though cold like you, unmov'd, and silent grown,

I have not yet forgot myself to stone.

All is not Heavn's while Abelard has part, Still rebel nature holds out half my heart; Nor pray'rs nor fasts its stubborn pulse restrain,

Nor tears, for ages, taught to flow in vain.
Hymnes, vous aussi tristes Saints, dont les statues enseignent à pleurer, que ne suis-je aussi froide que vous ! Mais comment faire pour me changer en marbre ? Tout mon être n'est pas encore à Dieu, la nature lui dispute la victoire. Ni jeûnes, ni prières n’ont pû calmer mon sang, \& mes larmes n'éteignent point mes feux.

\subsection{Traducción de Charles-Pierre Colardeau (1758)}

La obra fundamental en verso para el desarrollo del subgénero de la heroida en Francia en la segunda mitad del XVIII es la Lettre d'Héloïse à Abailard, traduction libre de M. Pope par M. C. *** (Au Paraclet, 1758) ${ }^{14}$.

Charles-Pierre Colardeau (1732-1776) comenzó su actividad literaria con poca fortuna: dos tragedias y una comedia sin ningún éxito que le hicieron abandonar la escena. Su notoriedad como escritor la encontró en la imitación de Pope en su Lettre Amoureuse d'Héloïse a Abailard (1758). El éxito de lectores llevó a la proliferación de otras imitaciones con los mismos tintes prerrománticos, de las que Colardeau sería considerado el creador (para unos) o el precursor (para otros), lo que él mismo defendió en otra heroida posterior: Armide à Renaud. En 1770, tradujo las dos primeras noches de la obra del inglés Edward Young, The Complaint: or, Night-Thoughts on Life, Death, \& Immortality, que dan a conocer al autor en Inglaterra, al que luego puso de moda el considerado traductor de los poetas ingleses de la Graveyard School, Pierre Le Tourneur. Acababa de ser elegido miembro de la Académie Française cuando falleció.

$\mathrm{Al}$ darle el título de «heroida» a su poema, Colardeau relanzó este subgénero de poemas. Se trata de una adaptación en alejandrinos, en la que utiliza un tono impersonal y lánguido, lleno de circunlocuciones y epítetos. La obra alcanzó éxito, según el «Avertissement» de una edición posterior: «A fait naître, depuis douze à quatorze ans, un torrent de petits Poèmes, sous le titre d'Hérö̈des, d'Épïtres, de Lettres, \&c. \&c. le plus grand nombre

14 Reeditada muchas veces en el mismo año de 1758 y después en 1766, 1769, 1777 y en el segundo tomo las Euvres de Colardeau (Colardeau, 1779: 1-45). De la obra de Colardeau hay una traducción en verso y un análisis en el trabajo de Soledad Díaz Alarcón (2010: 2553). La autora, como buena parte del grupo de investigación del profesor García Peinado durante varios años, se ocuparía de la poesía del XVIII en Francia e Inglaterra. 
dans l'oubli»15. Veamos las primeras estrofas de la traducción de Colardeau (1780: 25-27), que nos servirán para compararlas con la traducción de Aimé Feutry:

ÉPÎTRE D’HÉLOÏSE À ABAILARD

(Héloïse est supposée dans sa cellule, occupée à lire une lettre d'Abailard, et à y faire réponse)

Dans ces lieux habités par la simple innocence,

Où règne, avec la paix, un éternel silence,

Où les cœurs asservis à de sévères lois,

Vertueux par devoir, le sont aussi par choix ;

Quelle tempête affreuse, à mon repos fatal,

S'élève dans les sens d'une foible vestale ?

De mes feux mal éteints qui ranime l'ardeur?

Amour, cruel amour, renais-tu dans mon cœur?

Hélas ! je me trompais ; j'aime, je brûle encore.

O nom cher et fatal! Abailard ! je t'adore.

Cette lettre, ces traits à mes yeux si connus,

Je les baise cent fois, cent fois je les ai lus :

De sa bouche amoureuse Héloïse les presse.

Abailard ! cher amant !... mais quelle est ma faiblesse?

Quel nom dans ma retraite osé-je prononcer?

Ma main l'écrit... Eh bien ! mes pleurs vont l'effacer.

Dieu terrible, pardonne ; Héloïse soupire : $\mathrm{Au}$ plus cher des époux tu lui défends d'écrire ;

A tes ordres cruels Héloïse souscrit...

Que dis-je, mon cœur dicte... et ma plume obéit.

Prisons, où la vertu, volontaire victime, Gémit et se repent, quoique exempte de crime ;
EPÍSTOLA DE ELOÍSA A ABELARDO

(Eloísa está supuestamente en su celda, ocupada

leyendo una carta de Abelardo, a la que responde)

Lugares habitados por la simple inocencia,

donde con la paz reina, un eterno silencio, donde el alma oprimida por leyes tan severas,

virtuosos por deber, lo son por elección;

¿qué espantosa tormenta, mortal para mi calma,

se eleva en los oídos de una débil vestal?

¿De mis brasas aún tenues avivan el ardor?

Amor, cruel amor, irenaces en mi pecho?

iAy! Me equivocaba; amo, de ardor me abraso.

iMi querido y fatal Abelardo! Te adoro.

Esta letra, estos trazos, tan vistos por mis ojos,

los beso unas cien veces, cien veces los he leído:

con su amorosa boca Eloísa los aprieta.

¿Caro amante! iAbelardo!... ¿Mas cuál es mi flaqueza?

¿Qué nombre en mi retiro me atrevo a pronunciar?

Mi mano escribe... iBueno! Lo borrarán mis lágrimas.

Dios terrible, perdona; Eloísa suspira:

al más querido esposo le prohíbes escribir;

y tus crueles órdenes Eloísa las acepta...

Qué digo, mi alma dicta... Y mi pluma obedece.

Celdas, do la virtud, víctima voluntaria, gime y se arrepiente, aunque exenta de crimen;

${ }^{15}$ La fuente de esta referencia procede de VV.AA. (1792: 77). La traducción también la he encontrado en la edición ya citada (Colardeau, 1779: 21-40). 
Où l'homme, de son être imprudent destructeur,

Ne jette vers le ciel que des cris de douleur ;

Marbres inanimés, et vous, froides reliques,

Que nous ornons de fleurs, qu'honorent nos cantiques ;

Quand j'adore Abailard, quand il est mon époux,

Que ne suis-je insensible et froide comme vous!

Mon Dieu m'appelle en vain du trône de sa gloire :

Je cède à la nature une indigne victoire.

Les cilices, les fers, les prières, les vœux,

Tout est vain ; et mes pleurs n'éteignent point mes feux.

Au moment où j'ai lu ces tristes caractères,

Des ennuis de ton cœur secrets dépositaires,

Abailard, j'ai senti renaître mes douleurs.

Cher époux, cher objet de tendresse et d'horreurs,

Que l'amour, dans tes bras, avait pour moi de charmes!

Que l'amour, loin de toi, me fait verser de larmes!

Tantôt je crois te voir de myrte couronné, Heureux et satisfait, à mes pieds prosterné

Tantôt dans les déserts, farouche et solitaire,

Le front couvert de cendre et le corps sous la haire,

Desséché dans ta fleur, pâle et défiguré,

A l'ombre des autels, dans le cloître ignoré.

C'est donc là qu'Abailard, que sa fidèle épouse,

Quand la religion, de leur bonheur jalouse, Brise les nœuds chéris dont ils étaient lies,

Vont vivre indifférents, l'un par l'autre oubliés?

C'est là que, détestant et pleurant leur victoire,

Ils fouleront aux pieds et l'amour et la gloire?

Ah ! plutôt écris-moi : formons d'autres liens ; do el hombre, por su ser destructor imprudente,

tan solo lanza al cielo rugidos de dolor;

inanimados mármoles, vosotras frías reliquias,

que adornamos con flores que honran nuestros cánticos;

cuando adoro a Abelardo, cuando él es mi esposo,

¿por qué no soy insensible, fría como vosotras?

Mi Dios me llama en vano desde el trono en su gloria:

yo cedo a la Natura una indigna victoria.

Los cilicios, los hierros, las plegarias, los votos,

todo en vano; y mis lágrimas no ahogan mis fuegos.

El momento en que leo estos tus tristes trazos,

del hastío de tu pecho secretos mandatarios,

Abelardo, he sentido renacer mis dolores.

Caro esposo, objeto de ternura y horrores,

icuánto encanto tenía el amor, en tus brazos!

iCuántas lágrimas me hace derramar, de ti lejos!

A veces creo verte coronado de mirto,

feliz y satisfecho, a mis pies prosternado;

otras en los desiertos, salvaje y solitario,

la frente con cenizas, vestido cual asceta,

muy envejecido, mate y desfigurado,

refugiado en las aras, en el claustro ignorado.

¿Allí es donde Abelardo a su fiel esposa,

cuando la religión de su dicha celosa,

rompe los caros nudos con que estaban ligados?,

¿vivirán insensibles, mutuamente olvidados?

¿Allí es donde odiando y llorando su victoria,

van a pisotear el amor y la gloria?

iAy! Mejor escríbeme: forjemos otros vínculos; 
Partage mes regrets, je gémirai des tiens.

L'écho répétera nos plaintes mutuelles : L'écho suit les amants malheureux et fidèles.

Le sort, nos ennemis, ne peuvent nous ravir

Le plaisir douloureux de pleurer, de gémir : Nos larmes sont à nous, nous pouvons les répandre...

Mais Dieu seul, me dis-tu, Dieu seul doit y prétendre.

Cruel, je t'ai perdu, je perds tout avec toi : Tout m'arrache des pleurs, tu ne vis plus pour moi ;

C'est pour toi, pour toi seul que couleront mes larmes.

Aux pleurs des malheureux Dieu trouve-til des charmes? comparte mis pesares, yo gemiré los tuyos.

Repetirá el eco nuestros mutuos lamentos: acosa el eco a amantes infelices y fieles.

Del hado, los rivales, no pueden desposeernos

ni del placer amargo de llorar, de gemir:

son nuestras nuestras lágrimas, podemos esparcirlas...

Mas tú contestas: solo Dios puede afirmarlo.

Cruel, te he perdido, contigo pierdo todo:

todo me arranca lágrimas, para mí ya no vives;

es por ti, por ti solo, por quien brotarán ellas.

¿Dios halla algún encanto en las infaustas lágrimas?

\subsection{Traducciones posteriores influenciadas por la de Colardeau}

Tras la Lettre Amoureuse d'Héloïse á Abailard, un verdadero torrente de cartas amorosas y epístolas inundó Francia (Minois, 2019: 11-16), convirtiéndose el tema en un venero para los escritores, sobre todo para los poetas ${ }^{16}$. No obstante, después de un gran florecimiento entre 1760-1770, el subgénero decayó y perdió gran parte de su interés inicial. A pesar de ello, son dignas de citación algunas versiones, que en su momento aportaron vigor e intensidad a este tipo de poesía; citadas por orden cronológico, las más relevantes son estas ${ }^{17}$ :

${ }^{16}$ Para la heroida en la segunda mitad del XVIII, véase la obra de Renata Carocci (1988). La autora defiende que la heroida es un modo de modernizar el clasicismo, sobre todo cuando gira alrededor del tema del amor; a ese respecto, distingue la heroida «romancée» (cuyo argumento proviene de las novelas, tales como La Nouvelle Héloïse) y la heroida «romanesque» en la que, basándose en recuerdos o en modas literarias, el poeta deja libre curso a su imaginación.

${ }_{17}$ Una bibliografía exhaustiva francesa, antigua y moderna, sobre las obras de Abelardo, sobre las epístolas en cuestión y sus traducciones francesas se encuentra en la «Bibliothèque abélardienne» que contiene textos, biografías, estudios, etc. El interés por la correspondencia de los amantes no solo no decae, sino que atrae la atención de nuevos investigadores apasionados por las «Lettres». Cito, únicamente, algunas obras:

- HÉLOÏSE ET ABÉLARD: Lettres des deux amants. Traduction nouvelle par Sylvain Piron.

París,

Gallimard NRF, 2005.

- PIERRE ABÉLARD: Euvres biographiques, édition préparée par Nathalie Desgrugillers Clermont-Ferrand, Paléo, Sources de l'histoire de France, 2006.

- LETTRES D'ABÉLARD ET HÉLOÏSE, Texte établi et annoté par Eric Hicks et Thérèse Moreau, préface de Michel Zink, introduction de Jean-Yves Tilliette. Livre de poche, collection «Lettres Gothiques», texte intégral latin et français. París, Librairie Générale Française, 2007. 
- Henri Lambert d'Herbigny, marquis de Thibouville: Réponse d'Abeilard à Héloïse, $1758^{18}$.

- Claude-Joseph Dorat («chevalier Dorat»): Lettre de Abailard à Héloise, $1759^{19}$.

- Louis-Sébastien Mercier: Épître d'Héloïse à Abailard, imitation nouvelle de Pope, Londres, 1763.

- Sébastien-Marie-Mathurin Gazon-Dourxigné: Héloïse à son époux, héroïde nouvelle, $1765^{20}$.

- André-Charles Cailleau ${ }^{21}$ : Lettres et épîtres amoureuses d'Hélö̈se avec les réponses d'Abélard, 1772.

- Bernard Joseph Saurin²2: Épître d'Héloïse à Abelard, imitée de Pope, 1774 .

\section{Conclusiones}

En un comienzo, epístola amorosa en verso, ficticiamente dirigida por un héroe o personaje mitológico a una heroína, histórica o legendaria, o también a una pareja infiel o alejada por un destino desgraciado, la heroida fue inaugurada por el poeta latino Ovidio, que compuso cartas imaginarias de heroínas a sus amantes. Posteriormente, cosechó éxito en la Edad Media 23 y reverdeció en el siglo XVIII, en el que fue practicada por escritores notables en su época: Fontenelle, Feutry, Colardeau, Dorat, etc., los cuales incorporaron una nueva pareja a las ya tradicionales: Eloísa y Abelardo, en la que la verdadera amante es ella, ya que Abelardo no quiere seguir la relación, la cual va para él a contrapelo, puesto que su intención es purgar el mal hecho al enamorarse y alejarse de Dios.

- HÉLOISE- ABÉLARD, CORRESPONDANCE, édition bilingue, traduction, introduction et notes par Roland Denise Oberson. París, Hermann Littérature, 2008.

${ }^{18}$ Marqués y antiguo coronel de dragones, escritor de ingenio, aunque poco estimado en su época y prácticamente desconocido hoy.

19 Además de esta versión, Dorat escribió una segunda, en 1761, y una tercera en 1766 (la más larga). Sobre esta heroida remito al trabajo de Alfonso Saura (2009: 339-366). Con la «salonnière» Fanny de Beauharnais, su amante y quien lo mantuvo económicamente durante un tiempo, escribió en colaboración la novela L'Abailard supposé ou le Sentiment à l'épreuve.

${ }^{20}$ Autor de poco talento, pero con una gran facilidad para la escritura, tanto en verso como en prosa.

${ }^{21}$ Impresor y librero, autor satírico y dramático, conocido sobre todo por sus numerosos almanaques y opúsculos «poissards» o «polissons». He consultado una nueva edición revisada en cuya portada se lee lo siguiente: «Par Monsieur A. C. C** (Cailleau, 1781). Entre las obras en ella contenidas, se encuentra «Épitre d'Abeilard à Héloïse, son amante et son épouse ; imitée et mise en vers, Par M. A. C. C $^{* * *}$, d'après la Lettre D’Abeilard, du même, servant de Réponse à celle d'Héloïse par M. Pope» (Cailleau, 1781: 89-106).

22 Abogado del Parlamento durante quince años, ligado al partido filosófico y asiduo a los salones literarios de su época, tradujo obras inglesas. He consultado una publicación que data de seis años después (Saurin, 1780: 205-212).

23 Por ejemplo, el Salut d'amor occitano. 
El mérito de Colardeau, restaurador casi único de un subgénero que estaba casi olvidado 24 , fue el de utilizar todos los recursos que le ofrecía la elegía y el lirismo del «yo» para exaltar las pasiones. Con su imitación de Pope, Colardeau puso de moda una gran sensibilidad. Consecuentemente, la crítica literaria sobre esa época ha hecho de él un precursor del Romanticismo.

La definición etimológica que encontramos en el prestigioso Dictionnaire de Littré parece responder a la intención de Colardeau:

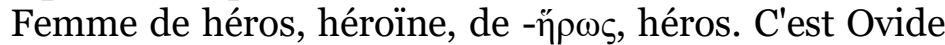
qui a imaginé le premier ce genre de poésie, prenant pour sujet les lettres des femmes ou maîtresses des héros à leurs maris ou amants ; il a intitulé ces pièces héroïdes, c'est-à-dire héroïnes; c'est ce mot d'héroïdes que nous avons détourné de son sens propre pour lui faire signifier un genre de poésie (Littré, 1873-1877: 2013).

Las traducciones e imitaciones francesas no dejaron de tener repercusión en España, cuyos escritores tradujeron e imitaron a su vez, logrando como en Francia un gran éxito de lectores ${ }^{25}$. En cuanto al original de Pope, se puede afirmar que en España la moda de Pope no existió, prácticamente, ya que los interesados del francés retraducían o imitaban (más que traducían) el poema de Pope. No obstante, existe una imitación editada en Salamanca por Tójar en 1796, en endecasílabos. Hay otra traducción en octavas reales de Juan María Maury, que se editó en Málaga en 1792 y se reeditó posteriormente en Madrid, en las dos primeras décadas del XIX; se trata de un poema de 62 octavas reales, en 1810. De $1892^{26}$, año en que las publicó el hispanista francés Alfred Morel-Fatio, son las imitaciones del abate Marchena, que versiona a Pope a través de Colardeau. Muy poco conocida parece ser la versión en alejandrinos de Silvina Ocampo incluida en la espléndida antología: Poetas líricos ingleses (selección de Ricardo Baeza, Buenos Aires, W. M. Jackson Inc. editores, 1952, pp. 143-153). La traducción de la poetisa argentina es un buen ejemplo de la similitud del traductor con el

24 Las Lettres portugaises traduites en français, de la religiosa portuguesa de Beja, Mariana Alcoforado, publicadas en 1669 (se sabe que su autor fue Gabriel de Guilleragues), son otro hito intermedio entre Ovidio y las heroidas. En ellas se dan todos los ingredientes característicos de las heroidas, sobre todo el de la amante abandonada y el de la falta de respuesta a las cartas.

25 Para una información más exhaustiva sobre este punto, véase la obra de Alfonso Saura Sánchez (2003).

${ }^{26}$ Francisco Lafarga (2020: en línea) concluye lo siguiente: «Aparte de algunas traducciones aisladas, se publicaron en España, a principios del siglo XIX, dos colecciones distintas de heroidas traducidas del francés (en 1804 y en 1807). Contienen poemas de Blin de Sainmore, Chamfort, Colardeau, Dorat (el más representado), La Harpe y otros autores, y los personajes que hablan -sacados de la historia, la leyenda o la literatura- son tan conocidos como Caín, Calipso, Sócrates, Safo, Ovidio, Catón, Séneca, Armida, el conde de Cominges o Barnevelt». 
poeta traducido sin tener que realizar su propia versión, algo muy común entre los poetas que traducen.

Finalmente, y por lo que se refiere a la historia de las Cartas de Eloísa y Abelardo, en las que la pasión amorosa se encuentra en ella (mencionada en ocasiones como «inventora» del amor femenino), ya que Abelardo generalmente trata de justificarse, la moda, lejos de decaer continúa en plena vigencia, sobre todo en Francia donde ocupa a todo tipo de humanistas, pero fundamentalmente a literatos, historiadores y filósofos. De ahí que el prestigioso filósofo francés Étienne Gilson (1884-1978), seducido por la historia de los dos amantes, escribiera en 1938 estas preciosas líneas, dirigidas a los famosos amantes enterrados en el cementerio de Père Lachaise:

On rapporte que, peu de temps avant sa mort, Héloïse avait pris les dispositions nécessaires pour être ensevelie avec Abélard. Lorsqu'on ouvrit sa tombe et qu'on l'y déposa près de lui, il étendit les bras pour l'accueillir, et les referma étroitement sur elle. Ainsi contée, l'histoire est belle, mais, légende pour légende, on admettrait plus volontiers qu'en rejoignant son ami dans la tombe, Héloïse ait ouvert les bras pour l'embrasser (Gilson, 2016: $146)^{27}$.

Nada extraño, tampoco, que la gran medievalista francesa Regine Pernoud (1909-1998), para exaltar el amor de los dos personajes, así como la importancia de estos en el devenir de la Edad Media, encabezara su monografía Héloïse et Abélard con una cita del filósofo y psicólogo Gaston Berger: «Il n'y a sur terre que deux choses précieuses : la première, c'est l'amour ; la seconde, bien loin derrière, c'est l'intelligence» (apud Pernoud, 1970: 7).

\section{REFERENCIAS BIBLIOGRÁFICAS}

ÁlVAREZ JURADO, Manuela (1998): La expresión de la pasión femenina a través de la epístola amorosa: el modelo portugués. Córdoba, Publicaciones de la Universidad de Córdoba y Obra Social y Cultural CajaSur.

AUERBACH, Erich (1967): «Philologie der Weltliteratur», in Gesammelte Aufsätze zur romanischen Literatur. Berna, Francke Verlag, 301-310.

BEAUCHAMPS, Pierre-François Godard de (1714): Les Lettres d'Héloïse et d'Abailard, mises en vers françois par le sieur P. F. G. de Beauchamps. París, Jacques Estienne.

BERMAN, Antoine (1984): L'épreuve de l'étranger. París, Gallimard.

${ }^{27}$ El propio Gilson es el autor del prólogo de una de las mejores ediciones de la correspondencia de los dos amantes: Abélard et Heloïse: Correspondance. Préface d'Étienne Gilson. Traduction d'Octave Gréard, présentée, revue et annotée par Édouard Bouyé (París, Éditions Gallimard, 2000). 
BOUYÉ, Édouard (2000): Abélard et Heloïse: Correspondance. Préface d’Étienne Gilson. Traduction d'Octave Gréard, présentée, revue et annotée par Édouard Bouyé. París, Éditions Gallimard.

BuRIN, Jeanne (1980): Très sage Héloïse. París, Librairie Hachette.

CAILlEAU, André-Charles (1781): «Épitre d'Abeilard à Héloïse, son amante et son épouse ; imitée et mise en vers, Par M. A. C. C**, d'après la Lettre D’Abeilard, du même, servant de Réponse à celle d'héloïse par M. Pope», in Collection précieuse des Lettres et Épistres d'Héloïse et d'Abeilard. Nouvelle édition. París, Cailleau, tome second, 89-106.

CAROCCI, Renata (1988): Les Héroïdes dans la seconde moitié du XVIII ${ }^{e}$ siècle (1758-1778). Fasano-París, Schena-Nizet.

COlARDEAU, Charles-Pierre (1779): Euvres de Colardeau, de l'Académie Française. París, Ballard et Le Jay. Tome Second.

COLARDEAU, Charles-Pierre (1780): «Epître amoureuse d'Héloïse à Abeilard, traduction libre de l'Anglais de Pope, par M. Colardeau», in VV.AA., Épîtres amoureuses d'Héloïse et d'Abeilard, traduites librement en vers et en prose [...]. Seconde Partie. París, s. i., 25-39.

COYER, Gabriel-Francois (1757): «Épître d'Héloïse à Abailard, traduite de l'Anglois de M. Pope», en Journal Etranger: Ouvrage Periodique. Avril 1757. París, Michel Lambert, 153-170.

COYER, Gabriel-Francois (1783): «Épître d'Héloïse à Abailard, traduite de l'Anglois de M. Pope», en Euvres Completes. París, Chez la veuve Duchesne. Tome second, 432-450.

DíAZ ALARCóN, Soledad (2010): «La influencia melancólica de los poetas prerrománticos ingleses en Francia». Hikma 9, 25-53.

DoRAT, Claude-Joseph [«chevalier Dorat»] (1759): Lettre de Abailard à Héloïse. Amsterdam, Pierre Chayer.

DRYDEN, John (1962): «The Preface to Ovid's Epistles, Translated by Several Hands (1680)», in George Watson (ed.), Of Dramatic Poesy and Other Critical Essays. Vol I. London/New York, J. M. Dent \& Sons/Dutton, 262273.

Du BoCAGE, Pierre-Joseph Fiquet (1751): «Épître d'Héloïse á Abalilard, traduite de l'Anglois $s$ de [...] Pope», in Mélange de différentes pièces de vers et de prose. Traduites de l'anglais d'après Mdmes Elize Haywood \& Suzanne Centlivre, Mrs Pope, Southern and autres. Berlin, s. i. Tome second.

DuchÊNE, Roger (2006): Comme une lettre à la poste. Les progrès de l'écriture personnelle sous Louis XIV. París, Fayard.

FEUTRY, Aimé (1751): Épitre d'Héloïse à Abélard, traduite de M. Pope, et mise en vers par M. Feutry. Londres, s.i.

FEUTRY, Aimé (1771): Opuscules poétiques et philologiques de M. Feutry. La HayeParís, Delalain.

FRANK, Armin Paul (1991): «Translating and Translated Poetry: the Producer's and the Historian's Perspectives», in Kitty M. van Leuven-Zwart y Ton Naaijkens (eds.), Translation Studies: The State of the Art. Proceedings of 
the First James S. Holmes Symposium on Translation Studies. Ámsterdam/Atlanta, Rodopi, 115-140.

García CALDERón, Ángeles (2007): «Eloise to Abelard de Alexander Pope». Alfinge 19, 49-80.

GARCÍA PEINADO, Miguel Ángel (2005): «La influencia en Francia de la poesía sepulcral inglesa del XVIII: Les Tombeaux (Aimé Feutry), Les Tombeaux Champêtres (Chateaubriand), Les Sépultures (Lamartine)». Hermeneus 7, 1-21.

GARCÍA YEBRA, Valentín (1988): «Protohistoria de la traducción» in Julio César Santoyo et al. (eds.), Fidus interpres. Actas de las primeras Jornadas $\mathrm{Na}$ cionales de Historia de la Traducción. León, Universidad de León, I, 11-23.

GAZON-DOURXIGNE, Sébastien-Marie-Mathurin (1765): Héloïse à son époux, héroïde nouvelle. París, Imprimerie de Sébastien Jorry.

GERVAISE, Armand («Dom Gervaise») (1722-23): Les véritables lettres d'Héloïse et d'Abailard, tirées d'un ancien manuscrit latin, trouvé dans la bibliothèque de François d'Amboise, conseiller d'État; traduites par l'auteur de leur vie, avec des notes historiques et critiques très curieuses, París, J. Musier. 2 vols.

GiLson, Étienne ([1938] 2016): Hélö̈se et Abélard. París, Librairie Philosophique J. Vrin.

GuIzot, M. et Mme (1853): Abailard et Héloïse. Essai historique. París, Didier.

HAMMOND, Brean (1986): Pope. Brighton, Harvester Press.

Holmes, James S. (1970): «Forms of Verse Translation and the Translation of Verse Form», in James S. Holmes y Anton Popovič (eds.), The Nature of Translation. The Hague, Mouton, 91-105.

JoHnson, Samuel (2009): «Pope», in Roger Lonsdale (ed.), The Lives of the Poets. A Selection. Oxford, Oxford University Press, 347-451.

LAFARGA, Francisco (2020): «La traducción de las letras francesas en el siglo XVIII», in Francisco Lafarga y Luis Pegenaute (eds.), Portal de Historia de la traducción en España. URL: http://phte.upf.edu/hte/siglo-xviii/lafarga-1/\#fn-11544-1.

LAFARGA, Francisco \& Luis PEGENAUTE (2004): «Introducción», in Francisco Lafarga y Luis Pegenaute (eds.), Historia de la Traducción en España. Madrid, Ambos Mundos, 1-18.

LASTRA, Antonio \& Ángeles GARCÍA CALDERÓN (2017): «De Eloísa a Abelardo», in Antonio Lastra (ed.), Ensayo sobre el hombre y otros escritos de Alexander Pope. Madrid, Cátedra, 139-150.

LITTRÉ, Émile (1863-1872, 2e édition revue et augmentée 1873-1877): Dictionnaire de la langue française. París, Hachette.

LÓPEZ ESTRADA, Francisco (1960): Antología de Epístolas. Barcelona, Labor.

MERCIER, Louis-Sébastien (1763): Épître d'Héloïse à Abailard, imitation nouvelle de Pope. Londres, s. i.

MinOIS, Georges (2019): Abélard, Hélö̈se et Bernard. París, Perrin.

MOYA DEL BAÑO, Francisca (1986): Heroidas de Ovidio. Texto revisado y traducido. Madrid, Consejo Superior de Investigaciones Científicas. 
Ovidio (1999): Arte de amar. Traducción de Juan Manuel Rodríguez Tobal. Madrid, Hiperión.

PASCAL, Jean-Noël (2003): “"Douces illusions et terribles alarmes”: brèves remarques sur les songes d'Héloïse dans les héroïdes françaises imitées de Pope», in Nathalie Dauvois et Jean-Philippe Grosperrin (eds.), Songes et Songeurs (XIII ${ }^{e}-X V I I I^{e}$ siècle). Québec, Presses de l'Université Laval, 221234 .

PERnOUd, Régine (1970): Héloïse et Abélard. París, Albin Michel.

PoPE, Alexander (1717): The Works of Mrs. Alexander Pope. London, Printed by W. Bowyer, for Bernard Lintot.

Rouben, César (1974): Bussy-Rabutin épistolier. París, Nizet.

SAURA SÁnCHEZ, Alfonso (2003): Las heroidas francesas y su recepción en España. Murcia, Servicio de Publicaciones de la Universidad de Murcia.

SAURA SÁNCHEZ, Alfonso (2009): «Les trois versions de la Lettre d'Abailard à Héloïse». Anales de Filología Francesa, 17, 339-366.

SAURIN, Bernard Joseph (1780): «Epitre [sic] d'Héloïse a Abeilard, imitée de Pope», in Lettres et épitres amoureuses d'Héloïse et d'Abeilard. Nouvelle Édition. Londres, s. i., 205-212. Tome Second.

Thibouville, Henri Lambert d'Herbigny, marquis de (1758): Réponse d'Abeilard à Héloïse. París, s. i.

VV.AA. (1780): Épîtres amoureuses d'Héloïse et d'Abeilard, traduites librement en vers et en prose, par MM. de Bussy-Rabutin, de Beauchamps, Pope, Colardeau, Dorat, Feutri, Mercier, G. Dourxigné, $C^{* * *}$, Saurin, \& Mercier. París, s. i. 2 vols. 